\title{
Desmame precoce em crianças atendidas na Estratégia Saúde da Família
}

\author{
Priscila Veras Santos ${ }^{1}$ \\ Maria do Carmo de Carvalho e Martins ${ }^{2}$ \\ Fabricio Ibiapina Tapety ${ }^{3}$ \\ Adriana de Azevedo Paiva ${ }^{4}$ \\ Fernandina Maria Neiva Santos Fonseca ${ }^{5}$ \\ Ana Karolinne da Silva Brito ${ }^{6}$
}

\section{RESUMO}

O objetivo deste estudo foi avaliar a prevalência de desmame precoce e fatores associados em crianças atendidas na Estratégia Saúde da Família. Trata-se de pesquisa quantitativa, descritiva e exploratória realizada com 241 crianças atendidas pela equipe de saúde. Para coleta dos dados foram usados um formulário e um questionário. Nas análises, para variáveis em que foram encontradas associações estatisticamente significativas foi realizado teste de regressão logística binária. A prevalência de desmame precoce foi de 58,51\%. Maiores proporções de desmame precoce ocorreram em crianças com idade entre um e três meses. Pertencer a classe econômica B/C e ter recebido orientação sobre amamentação no pré-natal apresentaram-se significativamente associados com o desmame precoce. A prevalência do desmame precoce foi elevada, e considerada semelhante à prevalência nacional e descrita para o estado do Piauí. Houve associação entre o desmame precoce, classe econômica B/C e ter recebido orientação sobre amamentação no pré-natal.

Descritores: Desmame; Estratégia Saúde da Família; Aleitamento Materno; Enfermagem Pediátrica.

\footnotetext{
${ }^{1}$ Nutricionista, Mestre em Saúde da Família. Professor da Faculdade Piauiense. Parnaíba, PI, Brasil. E-mail: priscilasantos00@gmail.com.

${ }^{2}$ Nutricionista, Doutora em Ciências Biológicas. Professora Titular do Centro Universitário UNINOVAFAPI. Professora Associada da Universidade Federal do Piauí. Teresinha, PI, Brasil. E-mail: mcmartins@uninovafapi.edu.br.

${ }^{3}$ Odontólogo, Doutor em Dentística Clínica. Professor do Centro Universitário UNINOVAFAPI. Teresinha, PI, Brasil. E-mail:

ftapety@uninovafapi.edu.br.

${ }^{4}$ Nutricionista, Doutor em Saúde Pública. Professor Adjunto da Universidade Federal do Piauí. Teresinha, PI, Brasil. E-mail: aapaiva@ufpi.edu.br.

${ }^{5}$ Médica, Mestre em Saúde da Família. Professora Assistente do Centro Universitário UNINOVAFAPI. Teresinha, PI, Brasil. E-mail: fmfonseca95@hotmail.com.

${ }^{6}$ Nutricionista. Discente do Programa de Pós-Graduação em Farmacologia, nível Mestrado, da Universidade Federal do Piauí. Teresinha, PI, Brasil. Email: anakarolinnesb@hotmail.com.
}

\section{Como citar esse artigo:}

Santos PV, Martins MCC, Tapety FI, Paiva AA, Fonseca FMNS, Brito AKS. Desmame precoce em crianças atendidas na Estratégia Saúde da Família. Rev. Eletr. Enf. [Internet]. 2018 [acesso em: ];20:v20a05. Disponível em: http://doi.org/10.5216/ree.v20.43690. 


\section{INTRODUÇÃO}

O aleitamento materno exclusivo (AME) é a alimentação ideal para crianças menores de seis meses de vida, sendo a partir dessa idade recomendada a introdução adequada de alimentação complementar. A amamentação exclusiva é eficaz no crescimento e desenvolvimento da criança, bem como na proteção de doenças, além da economia para o orçamento familiar ${ }^{(1)}$.

A implementação de ações de proteção e promoção do AM e da adequada alimentação complementar tem resultado em aumento dessa prática. Contudo, o comportamento do AME nas regiões brasileiras mostra-se heterogêneo, com maior prevalência na região Norte $(45,9 \%)$ e menor na região Nordeste $(37,0 \%)$, o que representa um enorme desafio para o Sistema de Saúde ${ }^{(2)}$.

Os benefícios da amamentação são inegáveis para o crescimento e desenvolvimento das crianças do ponto de vista biopsicossocial e para a saúde da mulher-mãe, família e sociedade, sendo um ato essencial para o ser humano. Entretanto, fatores socioeconômicos e culturais podem influenciar o desmame precoce, favorecendo o abandono da amamentação por sua não valorização ${ }^{(3)}$.

A atenção coletiva para mães deve focar a valorização das ações na proteção, promoção e o apoio ao AM. A Estratégia Saúde da Família (ESF) propõe a atuação de suas equipes junto às famílias em uma proposta interdisciplinar de assistência com ênfase na promoção da amamentação e educação para a saúde, contribuindo para a criação de hábitos saudáveis e prevenção de complicações. A promoção da amamentação é considerada uma prática importante para a redução da mortalidade infantil(4).

O desmame precoce constitui-se em problema frequente no Brasil e no mundo. Estudos evidenciam elevada prevalência de desmame precoce em países com diferenças econômicas e culturais em relação ao Brasil, e destacam dificuldades em incentivar e apoiar o prolongamento da amamentação. Nesse sentido, em estudo prospectivo de coorte realizado no Canadá, em que um grupo de mães forneceu detalhes completos aos três meses pós-parto, enquanto outro grupo continuou a fornecer informações aos seis meses pós-parto, a frequência de amamentação exclusiva de seis meses $(15,3 \%)$ foi considerada abaixo das recomendações nacionais e internacionais de amamentação(5).

No Piauí, estudo sobre a situação do AM no Estado demonstrou que $41,45 \%$ das crianças receberam AME até os seis meses de vida e que $58 \%$ estiveram em AM até o final do primeiro ano de vida ${ }^{(6)}$.

O presente estudo contribui com a produção de informações que servirão como subsídios para auxiliar no planejamento de intervenções pertinentes para as mães, de maneira a reduzir e/ou evitar a situação de desmame precoce, e nortear as condutas em relação ao AM e desmame na atenção básica. O objetivo deste trabalho foi avaliar a prevalência de desmame precoce e fatores a ele associados em crianças atendidas na ESF.

\section{METODOLOGIA}

Estudo descritivo, quantitativo e exploratório, desenvolvido em um município do nordeste brasileiro. Os serviços de saúde da atenção primária no município estudado contam com 33 equipes da ESF em toda zona urbana e quatro na zona rural. A pesquisa foi realizada com a população atendida apenas pelas 15 equipes da zona urbana que contavam com equipes multiprofissionais de saúde da família completas, com um total de 641 crianças atendidas. 
O tamanho da amostra foi calculado considerando margem de erro de $5 \%$, nível de confiança de $95 \%$, e população finita de 641 crianças, resultando em amostra de 241 crianças. A amostragem foi do tipo não probabilística, e foram incluídas informações de todas as crianças e mães atendidas nos dias de atendimento infantil nas unidades de saúde. Foram excluídas duas crianças cujas mães eram portadoras do vírus da imunodeficiência humana (HIV), quatro crianças prematuras (idade gestacional <37 semanas) ou com baixo peso ao nascer (peso $<2.500 \mathrm{~g}$ ), e 15 por não estarem acompanhadas pelas mães no momento da entrevista. A coleta de dados foi realizada de dezembro de 2013 a março de 2014.

Para obtenção de informações sociodemográficas e daquelas relacionadas ao nascimento, alimentação da criança, assistência à saúde, e sobre o apoio à amamentação, utilizou-se um formulário contendo questões fechadas. Os dados referentes à caracterização econômica foram obtidos através do questionário Critério de Classificação Econômica Brasil da Associação Brasileira de Empresas de Pesquisa - ABEP(7). Esse critério não tem a pretensão de classificar a população em termos de "classes sociais", sendo a divisão de mercado definida por ele exclusivamente de classes econômicas, com a função de estimar o poder de compra das pessoas e famílias urbanas $^{(7)}$.

Inicialmente os dados foram organizados por revisão manual dos formulários. As respostas das perguntas fechadas foram codificadas para facilitar as análises. Foi construído um banco de dados com o objetivo de corrigir as inconsistências. Nas análises foram utilizados os programas Microsoft Office Excel 2007 e Statistical Package for the Social Science (SPSS) versão 20.0. A associação entre variáveis foi testada por meio do teste qui-quadrado de Pearson, estabelecendo nível de significância em $p<0,05$. 0 teste exato de Fisher foi usado quando existiam menos que cinco observações em uma ou mais células. Para variáveis em que foram encontradas associações estatisticamente significativas foi aplicado teste de regressão logística binária.

O estudo foi aprovado pelo Comitê de Ética em Pesquisa do Centro Universitário UNINOVAFAPI, Certificado de Apresentação para Apreciação Ética (CAAE) n² 23179813.2.0000.5210. Participaram da pesquisa as crianças cujas mães concordaram com a inclusão das informações relacionadas com variáveis de estudo mediante assinatura de Termo de Consentimento Livre Esclarecido (TCLE).

\section{RESULTADOS}

A prevalência de desmame precoce entre as 241 crianças com idade até dois anos, atendidas na ESF na zona urbana de Parnaíba, PI, Brasil foi de 58,5\%. O desmame ocorreu com maior frequência nas faixas etárias de um a dois meses $(24,82 \%)$ e de dois e três meses $(20,57 \%)$ (Tabela 1$)$.

Quanto ao consumo alimentar das crianças (Tabela 2), mais da metade, em todas as faixas etárias analisadas, estava recebendo leite materno. O consumo de outros leites e alimentos foi mais frequente na faixa etária de 13 a 24 meses, apesar de ter apresentado frequência elevada também entre crianças com idade de zero a cinco meses e seis a 12 meses. Entre as crianças que consumiam leite materno nos seis primeiros meses, quase um terço consumia outros leites. Esses valores aumentaram para quase metade das crianças em idade a partir de seis meses. 
Tabela 1: Distribuição de crianças de zero a dois anos de idade atendidas na Estratégia de Saúde da Família, segundo idade de ocorrência do desmame precoce, no município de Parnaíba. Parnaíba, PI, Brasil, 2015.

\begin{tabular}{|c|c|c|c|}
\hline Variável & & $\mathbf{n}$ & $\%$ \\
\hline & Sim & 141 & 58,51 \\
\hline \multirow[t]{5}{*}{ Desmame precoce } & Não & 100 & 41,49 \\
\hline & Total & 241 & 100 \\
\hline & $<1$ & 10 & 7,09 \\
\hline & $1,0-2$ & 35 & 24,82 \\
\hline & $2,1-3$ & 29 & 20,57 \\
\hline \multirow[t]{4}{*}{ Idade do desmame (meses) } & $3,1-4$ & 27 & 19,15 \\
\hline & $4,1-5$ & 26 & 18,44 \\
\hline & $5,1-6$ & 14 & 9,93 \\
\hline & Total & 141 & 100 \\
\hline
\end{tabular}

Tabela 2: Aleitamento materno e consumo de outros leites e de outros alimentos por crianças atendidas pela Estratégia de Saúde da Família no município de Parnaíba. Parnaíba, PI, Brasil, 2015.

\begin{tabular}{|c|c|c|c|c|c|c|c|c|c|}
\hline \multirow{3}{*}{\multicolumn{2}{|c|}{ Variável }} & \multicolumn{8}{|c|}{ Idade (meses) } \\
\hline & & \multicolumn{2}{|c|}{$0-5$} & \multicolumn{2}{|c|}{$6-12$} & \multicolumn{2}{|c|}{$13-24$} & \multicolumn{2}{|c|}{ Total } \\
\hline & & n & $\%$ & $\mathbf{n}$ & $\%$ & n & $\%$ & $\mathbf{n}$ & $\%$ \\
\hline \multirow{3}{*}{$\begin{array}{l}\text { Estava recebendo leite } \\
\text { materno }\end{array}$} & Sim & 49 & 87,5 & 55 & 76,4 & 57 & 50,4 & 161 & 66,8 \\
\hline & Não & 7 & 12,5 & 17 & 23,6 & 56 & 49,6 & 80 & 33,2 \\
\hline & Total & 56 & 100,0 & 72 & 100,0 & 113 & 100,0 & 241 & 100,0 \\
\hline \multirow{3}{*}{ Consumo de outros leites } & Sim & 23 & 41,0 & 63 & 87,5 & 96 & 85,0 & 182 & 75,5 \\
\hline & Não & 33 & 59,0 & 9 & 12,5 & 17 & 15,0 & 59 & 24,5 \\
\hline & Total & 56 & 100,0 & 72 & 100,0 & 113 & 100,0 & 241 & 100,0 \\
\hline \multirow{3}{*}{ Consumo de outros alimentos } & Sim & 30 & 53,6 & 68 & 94,4 & 107 & 94,7 & 205 & 85,0 \\
\hline & Não & 26 & 46,4 & 4 & 5,6 & 6 & 5,3 & 36 & 15,0 \\
\hline & Total & 56 & 100,0 & 72 & 100,0 & 113 & 100,0 & 241 & 100,0 \\
\hline \multirow{4}{*}{$\begin{array}{c}\text { Criança em aleitamento } \\
\text { materno }\end{array}$} & Consumiu outros leites & 16 & 28,5 & 46 & 63,9 & 42 & 37,2 & 104 & 43,2 \\
\hline & $\begin{array}{c}\text { Não consumiu outros } \\
\text { leites }\end{array}$ & 33 & 59,0 & 9 & 12,5 & 16 & 14,2 & 58 & 24,1 \\
\hline & $\begin{array}{c}\text { Não está em aleitamento } \\
\text { materno }\end{array}$ & 7 & 12,5 & 17 & 23,6 & 55 & 48,6 & 79 & 32,7 \\
\hline & Total & 56 & 100,0 & 72 & 100,0 & 113 & 100,0 & 241 & 100,0 \\
\hline
\end{tabular}

Na Tabela 3 são apresentadas as características socioeconômicas das mães, segundo realização de desmame precoce. Mais de metade das mães tinha de 20 a 25 anos e escolaridade inferior a 11 anos de estudo. A maioria das mulheres referiu morar com seu companheiro (88\%) e informou prática de AME $(90,0 \%)$; embora $57,5 \%$ daquelas que referiram ter companheiro tenham realizado desmame precoce. Entre aquelas que não possuíam companheiro a frequência de desmame precoce atingiu 65,5\%.

Entre as mulheres pesquisadas, mais de metade era primípara, mais de dois terços delas não desenvolviam trabalho remunerado, e 71\% delas conseguiram manter o AME até o sexto mês. Entre as que trabalhavam, 62,3\% realizaram desmame precoce.

Desmame precoce foi referido por mais da metade das mulheres independente da licença maternidade. Vale ressaltar que $68,5 \%$ das mulheres não souberam informar sobre licença maternidade e nesse estrato mais de metade das mulheres $(56,3 \%)$ realizou desmame precoce. 
Tabela 3: Desmame precoce em crianças de zero a dois anos de idade atendidas na Estratégia de Saúde da Família segundo as características socioeconômicas da mãe no município de Parnaíba. Parnaíba, PI, Brasil, 2015.

\begin{tabular}{|c|c|c|c|c|c|}
\hline \multirow{2}{*}{ Variável } & & \multicolumn{3}{|c|}{ Desmame precoce } & \multirow{2}{*}{$\mathbf{P}$} \\
\hline & & $\mathbf{n}$ & c & $\%$ & \\
\hline \multirow{5}{*}{ Faixa etária (anos) } & $\leq 19$ & 34 & 21 & 61,7 & \multirow{5}{*}{0,450} \\
\hline & 20 a 25 & 85 & 51 & 60,0 & \\
\hline & 26 a 30 & 67 & 33 & 49,3 & \\
\hline & 31 a 35 & 35 & 23 & 65,7 & \\
\hline & $>35$ & 20 & 13 & 65,9 & \\
\hline \multirow{2}{*}{ Escolaridade materna (anos) de estudo) } & $<11$ & 142 & 77 & 54,2 & \multirow{2}{*}{0,106} \\
\hline & $\geq 11$ & 99 & 64 & 64,6 & \\
\hline \multirow{2}{*}{ Mora com companheiro } & Sim & 212 & 122 & 57,5 & \multirow{2}{*}{0,414} \\
\hline & Não & 29 & 19 & 65,5 & \\
\hline \multirow{3}{*}{ Escolaridade paterna (anos de estudo) } & $<$ de 11 & 104 & 63 & 60,5 & \multirow{3}{*}{0,593} \\
\hline & $>$ de 11 & 97 & 53 & 54,6 & \\
\hline & Não informado & 40 & 25 & 62,5 & \\
\hline \multirow{2}{*}{ Primeiro filho } & Sim & 118 & 74 & 62,7 & \multirow{2}{*}{0,194} \\
\hline & Não & 123 & 67 & 54,4 & \\
\hline \multirow{2}{*}{ Trabalhou na gravidez } & Sim & 77 & 48 & 62,3 & \multirow{2}{*}{0,408} \\
\hline & Não & 164 & 93 & 56,7 & \\
\hline \multirow{3}{*}{ Licença maternidade } & Sim & 41 & 26 & 63,4 & \multirow{3}{*}{0,609} \\
\hline & Não & 35 & 22 & 62,8 & \\
\hline & Não informado & 165 & 93 & 56,3 & \\
\hline \multirow{3}{*}{ Jornada de trabalho (horas/dia) } & $<$ de 6 & 7 & 2 & 28,5 & \multirow{3}{*}{0,172} \\
\hline & $6-12$ & 72 & 46 & 63,8 & \\
\hline & Não informado & 162 & 93 & 57,4 & \\
\hline \multirow{3}{*}{ Classe econômica } & B1/B2 & 26 & 16 & 61,5 & \multirow{3}{*}{0,000} \\
\hline & $\mathrm{C} 1 / \mathrm{C} 2$ & 77 & 61 & 79,2 & \\
\hline & $D / E$ & 138 & 64 & 46,4 & \\
\hline
\end{tabular}

Legenda: $\mathrm{n}$ = número total de mulheres no estrato; $\mathrm{c}$ = número de casos de desmame precoce.

Neste estudo 66,8\% dos partos foram realizados em maternidade credenciada à Iniciativa Hospital Amigo da Criança (IHAC), e 62,7\% das mães realizaram desmame precoce. Embora não tenha sido encontrada associação estatisticamente significativa entre essa variável e o desmame precoce, o valor de $p$ foi marginal $(p=0,059)$. Além disso, apesar da maioria dos partos terem sido realizados em IHAC o percentual de desmame precoce se manteve alto.

Em relação à classe econômica, mais de metade das mães (57,2\%) pertencia às classes econômicas D/E. Houve associação estatisticamente significativa entre pertencer às classes socioeconômicas $B / C$ e a realização de desmame precoce $(p=0,000)$.

Quanto às características de assistência à saúde (Tabela 4), a maioria das mães iniciou o pré-natal no primeiro trimestre $(74,3 \%)$ e fez mais de seis consultas. A fonte financiadora do pré-natal mais usada foi o Sistema Único de Saúde (SUS) (82,6\%).

Também o principal financiador dos partos foi o SUS $(87,2 \%)$, com mais de metade das mulheres referindo partos normais (56\%), e a maioria com alojamento conjunto integral $(88,7 \%)$ e duração de internação de até três dias (88,8\%). Quanto às orientações acerca da amamentação, 63,5\% não participaram de grupos de gestantes; e durante a internação $65,5 \%$ das mães receberam recomendações. No puerpério, $64,7 \%$ das mães foram visitadas 
em seu domicílio (VD) pela ESF, sendo para 53,1\% VD mensais de profissionais da ESF no pós-natal e, 61,8\% das mães foram orientadas sobre aleitamento pelo pediatra. Não houve associação entre essas variáveis e desmame precoce.

Tabela 4: Desmame precoce em crianças de zero a dois anos atendidas na Estratégia de Saúde da Família, segundo característica de assistência à saúde, no município de Parnaíba entre dezembro 2013 a março 2014. Parnaíba, PI, Brasil, 2015.

\begin{tabular}{|c|c|c|c|c|c|}
\hline \multirow{2}{*}{ Variável } & & \multicolumn{3}{|c|}{ Desmame Precoce } & \multirow{2}{*}{$\mathbf{p}$} \\
\hline & & $\mathbf{n}$ & c & $\%$ & \\
\hline \multirow{4}{*}{ Financiamento do pré-natal } & SUS & 199 & 116 & 58,2 & \multirow{4}{*}{0,468} \\
\hline & Convênio/Particular & 41 & 25 & 60,9 & \\
\hline & Não fez & 0 & 0 & 0 & \\
\hline & $1^{\circ}$ trimestre & 179 & 99 & 55,3 & \\
\hline \multirow[t]{2}{*}{ Início do pré-natal } & $2^{\circ}$ trimestre & 61 & 42 & 68,8 & \multirow[t]{2}{*}{0,088} \\
\hline & Não fez & 1 & 0 & 0 & \\
\hline \multirow{2}{*}{ Número de consultas } & $<6$ & 68 & 46 & 67,6 & \multirow{2}{*}{0,071} \\
\hline & $\geq 6$ & 173 & 95 & 54,9 & \\
\hline \multirow{2}{*}{ Parto em IHAC } & Sim & 161 & 101 & 62,7 & \multirow{2}{*}{0,059} \\
\hline & Não & 80 & 40 & 50 & \\
\hline \multirow{2}{*}{ Financiamento do parto } & SUS & 210 & 124 & 59,0 & \multirow{2}{*}{0,657} \\
\hline & Convênio/Particular & 31 & 17 & 54,8 & \\
\hline \multirow{3}{*}{ Tipo de parto } & Normal & 135 & 74 & 54,8 & \multirow{3}{*}{0,189} \\
\hline & Cesáreo & 106 & 67 & 63,2 & \\
\hline & Integral & 214 & 126 & 58,8 & \\
\hline \multirow[t]{2}{*}{ Alojamento conjunto } & Parcial & 11 & 6 & 54,5 & \multirow[t]{2}{*}{0,943} \\
\hline & Sem alojamento & 16 & 9 & 56,2 & \\
\hline \multirow{3}{*}{ Tempo de internação } & $<3$ dias & 214 & 126 & 58,8 & \multirow{2}{*}{0,741} \\
\hline & $>3$ dias & 27 & 15 & 55,5 & \\
\hline & Sim & 192 & 110 & 57,2 & 0,021 \\
\hline \multirow[t]{2}{*}{ Orientação sobre amamentação no pré-natal } & Não & 45 & 31 & 68,8 & \multirow[t]{2}{*}{$0,006^{*}$} \\
\hline & Não fez pré-natal & 4 & 0 & 0 & \\
\hline Orientação sobre amamentação em grupos de & Sim & 88 & 46 & 57,2 & \multirow{2}{*}{0,136} \\
\hline gestantes & Não & 153 & 95 & 62,0 & \\
\hline Orientação sobre amamentação na internação & Sim & 158 & 94 & 59,4 & \multirow{2}{*}{0,688} \\
\hline hospitalar & Não & 83 & 47 & 56,6 & \\
\hline Orientação sobre amamentação na alta & Sim & 186 & 109 & 58,6 & \multirow{2}{*}{0,956} \\
\hline hospitalar & Não & 55 & 32 & 58,1 & \\
\hline Orientação sobre amamentação de VD de & Sim & 156 & 93 & 59,6 & \multirow{2}{*}{0,636} \\
\hline puerpério & Não & 85 & 48 & 56,4 & \\
\hline Orientação sobre amamentação VD no pós- & Sim & 128 & 75 & 58,5 & \multirow{2}{*}{0,977} \\
\hline natal & Não & 113 & 66 & 58,4 & \\
\hline \multirow{3}{*}{$\begin{array}{l}\text { Orientação sobre amamentação em consultas } \\
\text { pediátricas }\end{array}$} & Sim & 149 & 91 & 61,0 & \multirow{3}{*}{0,587} \\
\hline & Não & 50 & 27 & 54,0 & \\
\hline & Não foi ao pediatra & 42 & 23 & 54,7 & \\
\hline
\end{tabular}

Legenda: $\mathrm{n}$ = número total de mulheres no estrato; $\mathrm{c}=$ número de casos de desmame precoce; * regressão logística binária.

A maioria das mães referiu ter recebido orientações sobre amamentação no período de pré-natal e $57,2 \%$ informaram ter realizado desmame precoce. Para esta variável houve associação estatisticamente significativa 
com o desmame precoce $(p=0,021)$. Na regressão logística binária foi encontrado risco da ocorrência de desmame precoce entre crianças cujas mães receberam orientação sobre amamentação no pré-natal $(p<0,006)$.

\section{DISCUSSÃO}

Neste estudo quase metade das crianças $(45,39 \%)$ foram desmamadas entre um e três meses de vida. Resultados diferentes foram encontrados em trabalho realizado em Picos (PI) com crianças menores de 12 meses atendidas na UBS, em que a interrupção do AME ocorreu antes de quatro meses de vida (31,1\%), com duração mediana do AME de um mês ${ }^{(8)}$.

AME até seis meses de vida ocorreu para quase metade das crianças. Estes resultados estão em concordância com dados de estudos nacionais e regionais. Neste sentido, na Segunda Pesquisa Nacional de Prevalência do Aleitamento Materno, desenvolvida pelo Ministério da Saúde em 2008, a prevalência de AME em menores de seis meses no Brasil foi de $41 \%^{(2)}$. No último estudo sobre a situação do AM no Piauí, $41,45 \%$ das crianças receberam AME até os seis meses de vida e $58 \%$ estiveram em AM até o final do primeiro ano de vida ${ }^{(6)}$. A prevalência de AME em Parnaíba foi ligeiramente maior que a encontrada para a região Nordeste em menores de seis meses (37,0\%), e semelhante àquela encontrada em Teresina na Pesquisa Nacional de Prevalência do Aleitamento Materno, com resultado que colocou essa cidade como a segunda capital nordestina com maior prevalência de AME $(43,7 \%)$.

Ao comparar os resultados encontrados em Parnaíba com estudos realizados em outros países, destaca-se que elevada prevalência de desmame precoce também foi um problema demonstrado em estudo de coorte realizado no Canadá, país desenvolvido da América do Norte, em que foram identificadas falhas por parte dos profissionais de saúde na orientação sobre amamentação(5). É importante ressaltar que apesar das diferenças econômicas e culturais desse país em relação ao Brasil, também existem dificuldades em incentivar e apoiar o prolongamento da amamentação.

A importância do AME nos seis primeiros meses é inquestionável, para promoção de um crescimento e desenvolvimento adequados das crianças e prevenção de doenças infecciosas, gastrointestinais e carências nutricionais ${ }^{(9)}$. Apesar de o AME ter sua importância reconhecida, o desmame precoce ainda é uma prática comum, especialmente entre os grupos menos favorecidos ${ }^{(2)}$. Dentre os fatores que têm sido referidos e que podem levar as mães a interromperem o AME destacam-se as influências que essas sofrem na sua forma de pensar e agir com relação ao aleitamento materno, contribuindo para a introdução precoce de água e alimentos, como sucos e leite, iniciados muitas vezes logo após a alta hospitalar. Essas influências podem partir de familiares que exercem forte influência quando se tratam de alimentação, nutrição e hidratação da criança ${ }^{(10)}$.

Quanto ao consumo alimentar das crianças, houve elevada frequência de consumo de outros leites e outros alimentos. Além disso, o não consumo de leite entre as crianças com idade entre zero e cinco meses foi encontrado em mais de metade das crianças. Resultados diferentes foram encontrados em outros estudos. Nesse sentido, segundo Bortolini et al ${ }^{(11)}$, resultados oriundos da Pesquisa Nacional de Demografia e Saúde demonstraram que o consumo de outros leites foi elevado nas faixas etárias menores de 12 meses e entre 12-36 meses. A recomendação mundial da prática de AME segundo a Organização Mundial de Saúde (OMS), também referida em trabalho desenvolvido no Canadá(5), preconiza que as crianças sejam amamentadas durante os seis meses de vida 
sem a introdução de alimentos complementares. Assim, o oferecimento de outros leites para crianças em situações desnecessárias deve ser inibido.

Aproximadamente metade das crianças deste estudo continuava a receber leite materno até os 13 a 24 meses de vida. Esse aspecto merece destaque, haja vista que a continuação da amamentação após os seis meses de vida é benéfica em virtude dos numerosos fatores imunológicos presentes no leite materno que protegem a criança contra infecções, além de conter gorduras que auxiliam no ganho de peso corporal(2).

Verificou-se que mais da metade das mães pertencia ao grupo etário de adultas jovens com idade de 20 a 30 anos. Em relação a esse aspecto, resultado parecido foi encontrado em trabalho realizado em Unidades de Saúde da Família (USF) de Pirpirituba (PB), em que 54\% das mães encontravam-se na faixa etária de 20 a 30 anos $^{(12)}$. Quanto às características socioeconômicas das mães, segundo realização de desmame precoce, mais de metade delas tinha escolaridade inferior a 11 anos de estudo, sem associação com o desmame precoce. Resultado semelhante foi encontrado no estudo realizado por meio de acompanhamento de mães e crianças de dois municípios do estado de São Paulo onde também não houve associação dessa variável com o desmame precoce; e a maioria das mães tinha idade entre 20 a 30 anos, baixa escolaridade e baixo poder aquisitivo(13).

Em relação aos antecedentes obstétricos, mais de metade das crianças não foi o primeiro filho das mães entrevistadas, e cerca de metade delas realizaram o desmame precoce. Ademais, não houve associação entre desmame e o fato de a criança ser ou não o primeiro filho. De forma semelhante, o desmame precoce não esteve associado à multiparidade entre puérperas que se encontravam no pós-parto em uma maternidade de Porto, Portugal, em que 39\% delas já tinham amamentado anteriormente e $72 \%$ haviam amamentado pelo menos por seis $\operatorname{meses}^{(14)}$.

A maioria das mulheres referiu morar com seu companheiro e informou a prática do AME; embora mais da metade daquelas que referiram ter companheiro tenha realizado desmame precoce. Entre as que não possuíam companheiro o desmame precoce também ocorreu para dois terços das crianças. Existem relatos diferentes em trabalhos realizados acerca dos fatores que podem combater para o desmame precoce. Entre mães de Feira de Santana (BA) onde seus parceiros valorizavam amamentação $(94,7 \%)$ apresentou-se como fator protetor contra o desmame precoce ${ }^{(15)}$. Por outro lado, a união estável pode ser um fator que contribui para maior duração do aleitamento materno, pois a atitude positiva do pai exerce grande efeito na motivação e na capacidade da mãe para amamentar e, é importante que o homem seja estimulado a participar mais diretamente no incentivo à amamentação(16).

Neste estudo mais de dois terços das mulheres não desenvolviam trabalho remunerado, com maior frequência de AME até o sexto mês. Contudo, maior frequência de desmame precoce ocorreu entre as mães que trabalhavam, embora sem associação significativa. Esses resultados assemelham-se àqueles encontrados em estudo feito em São Luís (MA) com o objetivo de caracterizar o aleitamento materno. Naquela capital de estado nordestino quase dois terços das mães (62,9\%) não exerciam atividade remunerada após o nascimento do filho, o que poderia beneficiar o $\mathrm{AM}^{(17)}$. Em pesquisa realizada com mães de crianças menores de um ano de idade em São João do Piauí (PI), o trabalho fora de casa foi considerado como fator que contribuiu para o desmame precoce $^{(18)}$, em virtude das dificuldades enfrentadas pelas mães em conciliar suas atividades fora do lar e ainda por inadequação ou ausência de suporte nos ambientes domésticos e de trabalho. 
Ao avaliar o desmame precoce segundo gozo de licença maternidade, observou-se que esse ocorreu tanto para mulheres que tiveram quanto para aquelas que não tiveram licença maternidade. Por outro lado, em pesquisa realizada no município de Serrana (SP) durante a segunda etapa da Campanha Nacional de Vacinação contra a poliomielite foi demonstrado que as mulheres sem gozo de licença-maternidade que trabalhavam fora de casa tiveram aproximadamente três vezes mais chance de interromper o AME. Ademais, as mães que não trabalhavam fora apresentaram, aproximadamente, duas vezes mais chance de desmamar seus filhos precocemente $^{(19)}$.

A licença maternidade é um direito das mulheres garantido pela Constituição Federal de 1988 com o objetivo de assegurar a prática do aleitamento. E, mediante incentivo fiscal, empresas privadas que aderem ao Programa Empresa Cidadã, prorrogando para 180 dias a licença maternidade, recebem como benefício redução dos impostos ${ }^{(2)}$. Em trabalho sobre a influência da prorrogação da licença maternidade para seis meses na duração do AME com mães usuárias de um Centro de Educação Infantil na cidade de Maringá (PR), essa prorrogação possibilitou que as mães usuárias amamentassem exclusivamente seus filhos por tempo mais longo, mas ainda assim não pelo período de seis meses recomendado pela OMS; e o principal motivo referido por elas para a interrupção do AME foi o retorno ao trabalho(20).

Em relação à classe econômica, mais de metade das mães pertencia às classes econômicas $D / E$, e pertencer às classes socioeconômicas $B / C$ esteve associado com realização de desmame precoce. Assim, foi possível observar que mulheres de classe econômicas mais altas não mantiveram o AME até seis meses. Resultados diferentes foram encontrados em estudo realizado com mulheres atendidas em duas maternidades públicas em Londrina (PR), cujo objetivo era caracterizar a duração do AME e os motivos de desmame precoce, em que pertencer a classe econômica baixa constituiu-se em fator de risco para o desmame precoce ${ }^{(21)}$.

Entre as mães de crianças de Parnaíba (PI) que tiveram seis ou mais consultas de pré-natal, quase metade realizaram AME durante seis meses. Concordando com este resultado, em pesquisa realizada na Unidade Básica de Saúde da Família (UBSF) no interior do Ceará, mulheres que realizaram seis ou mais consultas de pré-natal conseguiram amamentar por mais tempo em relação àquelas que realizaram menos de seis consultas ${ }^{(22)}$.

Neste estudo a maioria dos partos foram realizados em maternidade credenciada ao IHAC. Apesar disso, a prevalência de desmame precoce foi elevada. É interessante destacar que um estudo realizado no alojamento conjunto de um hospital "Amigo da Criança” no Rio Grande do Norte, onde foram feitas inúmeras indicações de suplemento alimentar desnecessárias e precipitadas, podendo dificultar o aleitamento materno e favorecendo o desmame precoce ${ }^{(23)}$.

Entre as mães de crianças pesquisadas neste trabalho, a maioria referiu ter recebido orientações sobre amamentação no período de pré-natal, e essa variável esteve associada com o desmame precoce. Estudo sobre avaliação da adequação do processo da assistência pré-natal no município de Vitória (ES), cerca de 30\% das gestantes foram orientadas, durante o acompanhamento pré-natal, quanto ao aleitamento materno exclusivo até o sexto mês de vida e a continuidade com alimentação complementar até o segundo ano de vida ou mais ${ }^{(24)}$.

As informações dadas pelos profissionais de saúde durante o pré-natal são importantes para o sucesso do aleitamento, embora sejam mais eficientes quando combinadas com informações passadas continuamente nos períodos perinatal e pós-natal. Destaca-se a importância do puerpério imediato como fator decisivo para o sucesso 
da amamentação, pois é quando as mães enfrentam as maiores dificuldades com o aleitamento materno. A visita domiciliar pelos profissionais da ESF atende às especificidades e particularidades de cada família, como um instrumento cotidiano para ações de promoção da saúde ${ }^{(25)}$.

O delineamento transversal é uma limitação deste estudo, pois impossibilita traçar relação de causa e efeito. $O$ tamanho da amostra pequeno diminui o poder para detectar as diferenças entre as variáveis estudadas; e o fato de não ter incluído crianças assistidas por equipes da ESF da zona rural do município, apesar de constituída por crianças assistidas por todas as equipes multiprofissionais completas da zona urbana diminui a possibilidade de generalização para o município como um todo. Entretanto, os resultados obtidos poderão ser utilizados como referência para políticas voltadas à realidade local, regional ou mesmo de áreas ou países com diferenças econômicas e culturais em relação à situação existente no Brasil, sem perder de vista as tendências observadas na atualidade e que resultem de reflexão epidemiológica com vistas à aplicação de seus resultados para a prática clínica.

\section{CONCLUSÃO}

A prevalência do desmame precoce foi elevada, e considerada semelhante à prevalência nacional e descrita para o estado do Piauí/Brasil, bem como para outras cidades do país e mesmo de outros países, a exemplo do Canadá, economicamente mais desenvolvido e com grandes diferenças culturais, indicando que o desmame precoce é um problema mundialmente importante. Houve associação entre o desmame precoce, classe econômica B/C e orientação sobre amamentação no pré-natal.

Qualquer que seja o fator que possa contribuir para a ocorrência de desmame precoce ele deve ser analisado. É importante procurar tornar o AM um ato de prazer e dedicação e não uma obrigação, de forma a contribuir para a qualidade de vida da mãe e seu filho. Assim, para reduzir o desmame precoce, cabe ao profissional de saúde incentivar o aleitamento materno, apoiando e instruindo a gestante e a nutriz, através do acompanhamento pré-natal cuidadoso, com formação de grupos de gestantes, onde o interesse das mães em participar seja continuamente estimulado. Ademais, é necessário ajudar na prática da amamentação durante a internação hospitalar, realizar visitas domiciliares durante o puerpério e, promover mais campanhas de incentivo ao aleitamento.

São necessários estudos longitudinais para determinar relação de causa e efeito, bem como estudos de intervenção que avaliem o impacto, na atenção básica, de políticas de saúde que levem em conta as condições existentes a fim de contribuir para melhorar a situação do aleitamento materno exclusivo.

\section{FINANCIAMENTO}

O estudo contou com o apoio financeiro do Instituto de Ensino Superior do Piauí Ltda.

\section{REFERÊNCIAS}

1. Dias EG, Freitas ALSA, Martins HCSC, Martins KP, Alves JCS. Vantagens da amamentação e alterações no estilo de vida da Lactante. Rev. Contexto \& Saúde [Internt]. 2016 [cited 2017 Oct 30] ; 31(16):26-33, Available from:

https://www.revistas.unijui.edu.br/index.php/contextoesaude/article/view/5763.http://dx.doi.org/10.21527/2176-

$\underline{7114.2016 .31 .25-33 .}$ 
2. Brasil. Ministério da Saúde. Secretaria de Atenção a Saúde. Departamento de Ações Programáticas e Estratégicas. II Pesquisa de Prevalência de Aleitamento Materno nas Capitais Brasileiras e Distrito Federal / Ministério da Saúde, Secretaria de Atenção a Saúde, Departamento de Ações Programáticas e Estratégicas. Brasília: Editora do Ministério da Saúde [Internet].; 2009 [cited 2017 Maio 15]. Disponível em: http://bvsms.saude.gov.br/bvs/publicacoes/pesquisa_prevalencia_aleitamento_materno.pdf. 3. Batistel C, Tanaka C, Sant'Ana J, Paschoal AS. A importância das orientações do enfermeiro no aleitamento materno considerando os fatores socioeconômicos e culturais da gestante no desmame precoce. Rev Eletr da Facul Evangelica [Internet].; 2012[ cited 2017 Maio 15] ; 2 (3): 2-17. Disponível em:

http://www.fepar.edu.br/revistaeletronica/index.php/revfepar/article/view/52.

4. Battaus MRB, Liberali RA. Promoção do aleitamento materno na estratégia de saúde da família - revisão sistemática. Rev. APS. [Internet].; 2014[ cited 2017 Maio15];17(1):93-100.Disponível em: https://aps.ufjf.emnuvens.com.br/aps/article/view/1843/789. 5. Jessri M, Farmer AP, Maximova K, Willows ND, Bell RC. Predictors of exclusive breastfeeding: observations from the Alberta pregnancy outcomes and nutrition (APrON) study. BMC Pediatrics [Internt]. 2013 [cited 2017 Oct 30]; 77 (13) :02-14. Available from: https://bmcpediatr.biomedcentral.com/articles/10.1186/1471-2431-13-77.

6. Ramos CV, Almeida JAG de, Alberto NSMC, Teles JBM, Saldiva SRDM. Diagnóstico da situação do aleitamento materno no Estado do Piauí, Brasil. Cad. Saúde Pública [Internet].; 2008 [cited 2017 Maio15] ; 24( 8 ): 1753-1762. Disponível em:

http://dx.doi.org/10.1590/S0102-311X2008000800004.

7. Brasil. ABEP. Critério de classificação econômica Brasil. 2015. [cited 2017 nov 02]; Disponível em: http://www.abep.org/Servicos/Download.aspx?id=09.

8. Silva,DC Araújo NL, Lima LHO, Oliveira EAR, Carvalho ES, Duailibe FT, Formiga LMF. Alimentação dos lactentes e fatores relacionados ao aleitamento materno. Rev Rede de Enfer Nordeste [Internet].; 2013 [cited 2017 maio 15]; 14( 6): $1064-1072$. Disponível em: http://www.redalyc.org/articulo.oa?id=324029419002.

9. Santos AJAO, Bispo AJB, Cruz LD. Padrão de aleitamento e estado nutricional de crianças até os seis meses de idade. HU Revista, 2016. 42 (2), p. 119-124.

10. Rocha MG, Costa ES. Interrupção precoce do aleitamento materno exclusivo: experiência com mães de crianças em consultas de puericultura. Rev Bras Promoç Saúde [Internet]. 2015 [cited 2017 Oct 30]; 28(4): 547-552. Available from:

http://dx.doi.org/10.5020/18061230.2015.p5 47.

11. Bortolini GA, Vitolo MR, Gubert MB, Santos LMP. Iniquidades sociais influenciam a qualidade e a diversidade da dieta de crianças brasileiras de 6 a 36 meses. Cad. Saúde Pública [Internet]. 2015 Nov [cited 2017 Oct 30] ; 31( 11): 2413-2424. Available from: http://dx.doi.org/10.1590/0102-311X00153414.

12. Félix FilhoFA, Shitsuka C, Moriyama CM, Duarte DA, Pacheco J, Ferreira M, Barbosa I. Fatores relacionados ao desmame precoce entre nutrizes cadastradas em uma unidade de saúde da família. Rev. Saúde.Com [internet].; 2016 [cited 2017 Maio 15]; 12(2): 588592. Disponível em: http://www.uesb.br/revista/rsc/ojs/index.php/rsc/article/view/366.

13. Rocha NB, Garbin AJI, Garbin CAS, Saliba O, Moimaz SAS. Estudo Longitudinal sobre a Prática de Aleitamento Materno e Fatores Associados ao Desmame Precoce Pesq Bras Odontoped Clin Integr [Internet]. 2013 [cited 2017 Maio 15];13(4):337-42. Disponível em: https://repositorio.unesp.br/bitstream/handle/11449/133404/ISSN1519-0501-2013-13-04-337-

342. pdf? sequence=1\&isAllowed=y.

14. Dias A, Monteiro T, Oliveira D, Guedes A, Godinho C, Alexandrino AM. Aleitamento materno no primeiro ano de vida: prevalência, fatores protetores e de abandono. Acta Pediatr Port [Internt]. 2013 [cited 2017 Oct 30] ; 44(6):313-8. Available from: http://actapediatrica.spp.pt/article/view/2719/2754 .

15. Vieira TO, Vieira GO, Oliveira NF, Mendes CMC, Giugliani ERJ, Silva LR. Duration of exclusive breastfeeding in a Brazilian population: new determinants in a cohort study. BMC Pregnancy and Childbirth [Internet]. 2014 [cited 2017 Oct 30]; 175(14): 19. Available from: https://www.ncbi.nlm.nih.gov/pubmed/24885939.

16. Matos NJ, Oliveira VS de, Coelho MMF, Dodt RCM, Moura DJM. Percepção e apoio dispensado pelo pai na manutenção do aleitamento materno. Rev enferm UFPE on line [Internet].; 2015 [cited 2015 June 01];9(5): 7819-25. Disponível em:

http://www.revista.ufpe.br/revistaenfermagem/index.php/revista/article/download/6185/12197.

17. Rieth NFA, Coimbra LC. Caracterização do aleitamento materno em São Luís, Maranhão. Rev Pesq Saúde [Internet].; 2016 [cited 2017 Maio 15]; 17(1): 7-12. Disponível em:

http://www.periodicoseletronicos.ufma.br/index.php/revistahuufma/article/viewFile/5487/3360.

18. Araújo OD, Leal AB, Sousa AF, Florentino ECL, Silva LRB, Menezes CC. Perfil do aleitamento materno exclusivo e fatores determinantes do desmame precoce em município do semi-árido da Região Nordeste. Rev. Bras. Pesq. Saúde [Internet].; 2014 [cited 2017 Maio 15]; 16(3): 84-91. Disponível em: http://periodicos.ufes.br/RBPS/article/view/10155/6896.

19. Queluz MC, Pereira MJB, Santos CB, Leite AM, Ricco RG. Prevalência e determinantes do aleitamento materno exclusivo no município de Serrana, São Paulo, Brasil.Rev Esc Enferm USP [Internet].; 2012 [cited 2017 Maio 15]; 46(3):537-43. Disponível em: http://www.scielo.br/pdf/reeusp/v46n3/02.pdf.

20. Ferreira GR, Dartibale EF, Bercini LO. Influência da prorrogação da licença maternidade para seis meses na duração do aleitamento materno exclusivo. Rev Min Enferm [Internet].; 2013 [cited 2017 Maio 15]; 17(2):398-404.Disponível em: http://www.reme.org.br/artigo/detalhes/658. 
21. Barbieri MC, Ferrari RAP, Cardelli AAM, Marrero T, Klebis DC, Tacla MTGM. Duração do aleitamento materno: caracterização de mulheres atendidas em duas maternidades públicas. J Nurs Health [Internet].; 2012 [cited 2017 Maio 15]; 2(2):475-89. Disponível em: https://periodicos.ufpel.edu.br/ojs2/index.php/enfermagem/article/view/3474/2859.

22. Uchoa JL, Rodrigues AP, Joventino ES, Almeida PC, Oria MOB, Ximenes LB. Autoeficácia em amamentar de mulheres no prénatal e no pós-parto: estudo longitudinal. Rev Enferm UFSM [Internet].; 2016 [cited 2017 Maio 15]; 6(1): 10-20. Disponível em: https://periodicos.ufsm.br/reufsm/article/view/17687.

23. Pinheiro JMF, Menêzes TB, Brito KMF, Melo ANL, Queiroz DJM, Sureira TM. Prevalência e fatores associados à prescrição/solicitação de suplementação alimentar em recém-nascidos. Rev. Nutr. [Internet]. 2016 June [cited 2017 Oct 30]; 29(3):367-75. Available from: http://dx.doi.org/10.1590/167898652016000300007.

24. Polgliane RBS, Leal MC, Amorim MHC, Zandonade E, Santos NET. Adequação do processo de assistência pré-natal segundo critérios do Programa de Humanização do Pré-natal e Nascimento e da Organização Mundial de Saúde. Ciênc. saúde coletiva [Internet]. 2014 July [cited 2017 Oct 30]; 19(7): 1999-2010. Available from: http://dx.doi.org/10.1590/141381232014197.08622013.

25. Batista KRA, Farias MCAD, Melo WSN. Influência da assistência de enfermagem na prática da amamentação no puerpério imediato. Saúde debate [Internet].; 2013 [cited 2017 Maio 15]; 37 (96): 130-138. Disponível em:

http://www.scielo.br/pdf/sdeb/v37n96/15.pdf. 